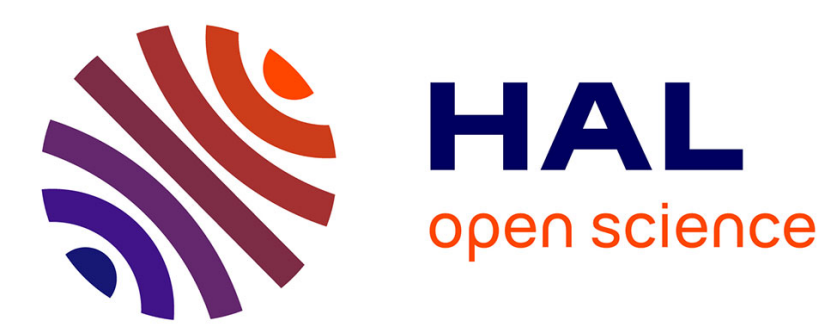

\title{
Temperature dependence of ionization energies of deep bound states in semiconductors
}

\author{
A. Mircea, A. Mitonneau, J. Vannimenus
}

\section{To cite this version:}

A. Mircea, A. Mitonneau, J. Vannimenus. Temperature dependence of ionization energies of deep bound states in semiconductors. Journal de Physique Lettres, 1977, 38 (1), pp.41-43. 10.1051/jphyslet:0197700380104100 . jpa-00231318

\section{HAL Id: jpa-00231318 https://hal.science/jpa-00231318}

Submitted on 1 Jan 1977

HAL is a multi-disciplinary open access archive for the deposit and dissemination of scientific research documents, whether they are published or not. The documents may come from teaching and research institutions in France or abroad, or from public or private research centers.
L'archive ouverte pluridisciplinaire HAL, est destinée au dépôt et à la diffusion de documents scientifiques de niveau recherche, publiés ou non, émanant des établissements d'enseignement et de recherche français ou étrangers, des laboratoires publics ou privés. 


\author{
Classification \\ Physics Abstracts \\ $7.160-7.170-8.140-8.272$
}

\title{
TEMPERATURE DEPENDENCE OF IONIZATION ENERGIES OF DEEP BOUND STATES IN SEMICONDUCTORS (*)
}

\author{
A. MIRCEA, A. MITONNEAU
}

Laboratoires d'Electronique et de Physique appliquée, 3, avenue Descartes, 94450 Limeil-Brévannes, France

\author{
and J. VANNIMENUS
}

Groupe de Physique des Solides, Ecole Normale Supérieure, 75231 Paris, France

(Reçu le 14 octohre 1976. révisć le 9 novembre 1976. accepté le 17 noremhre 1976)

\begin{abstract}
Résumé. - Nous proposons que le coefficient de température de l'énergie d'ionisation d'un niveau profond soit déterminé à partir de mesures des taux d'émission et de capture des porteurs, à l'aide des techniques de capacité transitoire telles que DLTS. Pour illustrer la méthode nous examinons deux pièges à électrons et trois pièges à trous dans GaAs. Un des pièges à trous semble conserver une différence d'énergie constante par rapport à la bande de conduction.
\end{abstract}

Abstract. - We explain that the temperature coefficient of the ionization energy of a deep level can be determined from measurements of carrier emission rate and capture rate, using transient capacitance techniques such as DLTS. Two electron traps and three hole traps in GaAs are examined as an illustration. One of the hole traps appears to be strongly pinned to the conduction band.

In a limited range of temperatures, the temperature dependence of the ionization energy of a bound state in an ordered, non-degenerate semiconductor may be assumed to be linear :

$$
E_{i}=E_{i 0}-\alpha T .
$$

In this letter we propose that the temperature coefficient be experimentally obtained from transient capacitance measurements on Schottky barriers.

The knowledge of the temperature coefficient $\alpha$ is useful in practical device applications. In view of the fact that it is related to the entropy of ionization, it may also - and it is this aspect that we would like to emphasize here - serve as a guide in the process of understanding the bound state, helping to trace back its physico-chemical origin. Recently, Van Vechten and Thurmond [1] have discussed this problem starting from simple considerations of the effect of bound carriers upon lattice vibration modes and the localization of the bound carriers around different types of defect centers. They have shown that (i) for Coulombic defects, $\alpha=P\left(E_{i 0}, T\right) \alpha_{G}$, where $\alpha_{G}$ is the temperature coefficient of the band gap, while $P$

$\left.{ }^{*}\right)$ Work supported in part by the Direction Générale de la Recherche Scientifique et Technique (D.G.R.S.T.). is essentially zero for hydrogenic impurities and increases for defects with central cell corrections, so that it may approach unity for very deep levels; (ii) for neutral defects with weak binding potentials (isoelectronic impurities, vacancies in $\mathrm{Si}$ or $\mathrm{Ge}$, group 3 vacancies in 3-5 semiconductors), $\alpha \simeq \alpha_{\mathrm{G}}$.

It appears, however, that very little experimental information is available concerning $\alpha$, especially in 3-5 semiconductors. This scarcity is related to the difficulties which exist in the experimental determination.

The direct way of obtaining $\alpha$ is from extrinsic optical absorption or photo-conductivity thresholds as a function of temperature. Reliable thresholds are, however, difficult to extract $[2,3]$ due to such facts as the additional contribution of other levels, limited sensitivity or resolution, variation of the shape of the individual contributions with temperature, and inadequate knowledge of what this shape should be in order to use curve fitting techniques.

Ionization energies may also be determined indirectly, from experiments which are analyzed in terms of thermal activation energies, such as Hall effect, conductivity, and other thermally stimulated effects. The temperature dependent part of the ionization energy then results in a pre-exponential constant 
factor $\exp (\alpha / k)$ which in most cases cannot be separated from the other pre-exponential factors of the problem.

The transient capacitance experiment $[3,4]$ is also of this type, however, it is possible in this case to obtain the pre-exponential factor quite readily and accurately, thus allowing the determination of $\alpha$ for many deep levels. As a matter of fact, the data necessary for calculating $\alpha$ have already been published for several of these levels [5-7, 14], but the contribution of the temperature coefficient $\alpha$ has not been recognized [7, 9].

We have especially in mind the dynamical form of the transient capacitance experiment (DLTS) [4], since this allows one to differentiate easily between the different deep states which may be present in a given sample. With this technique one can measure, in a range of temperatures, both the emission rate $e_{n}\left(e_{p}\right)$ of electrons (holes) from a definite deep level to the conduction (valence) band and the capture rate $c_{n} n\left(c_{p} p\right)$ of carriers into the same level. From the capture rate, knowing the free carrier density, one gets the capture cross-section $\sigma_{n}\left(\sigma_{p}\right)$. Now, $e_{n}\left(e_{p}\right)$ are related to $\sigma_{n}\left(\sigma_{p}\right)$ through the equations of detailed balance; e.g., for electrons

$$
e_{n}=N_{\mathrm{c}} v_{\mathrm{th} . n} \sigma_{n} g_{n} \exp \left(-E_{i \mathrm{c}} / k T\right)
$$

where $g=$ degeneracy factor, $v_{\text {th }}=$ thermal velocity, $N=$ effective density of states; the subscripts $n, c$ stand for electrons and the conduction band. It has been shown and discussed by Henry and Lang [5] that, for some of the deep states, the capture crosssection itself has an exponential dependence upon $1 / T:$

$$
\sigma_{n}=\sigma_{\infty} \exp \left(-E_{b} / k T\right)
$$

where both $\sigma_{\infty}$ and $E_{b}$ are obtained from the experimental capture rate data; eq. (3) may be also used as an empirical expression for all the capture crosssections, even if $E_{b}$ may not have physical meaning. Replacing (3) and (1) into (2) leaves us with the following equation

where

$$
e_{n}=\beta_{n} T^{2} \exp \left(-E_{a c} / k T\right)
$$

and

$$
E_{a \mathrm{c}}=E_{i \mathrm{c} 0}+E_{b}
$$

$\beta_{n}=\left(4 \sqrt{6} \pi^{3 / 2} h^{-3} m_{n}^{*} k^{2}\right) \sigma_{\infty} g_{n} \exp \left(\alpha_{c} / k\right)$

where $m^{*}$ is the carrier effective mass; expressions similar to (2) and (6), with $\left(g_{p}\right)^{-1}$ replacing $g_{n}$, hold for holes. It is clear from (4)-(6) that both $E_{i 0}$ and $\alpha$ can be extracted from the experimentally determined parameters $\beta, E_{a}, \sigma_{\infty}$ and $E_{b}$. More precisely,

$$
\alpha_{c}^{\prime}=\alpha_{c}+k \ln g_{n}
$$

( $\alpha_{v}^{\prime}=\alpha_{v}-k \ln g_{p}$ for holes) is extracted from these parameters; then $\alpha$ is calculated using currently accepted values for $g_{n}\left(g_{p}\right)$ (see Table I).

As already mentioned in previously reported interpretations of transient capacitance data the contribution of $\alpha$ to the pre-exponential factor (6) has been overlooked; this has led to an apparent disagreement between the two members of eq. (6). This disagreement has been recognized for a long time, e.g. for some deep levels in silicon [10], but it has not been understood. In the recent DLTS measurements of deep levels in GaAs, the disagreement is by a factor varying between 20 and several hundred.

In order to be able to use (2) for extracting $\alpha$, it is of course necessary that the emission rates and the

\begin{tabular}{|c|c|c|c|c|c|c|c|c|}
\hline \multirow{3}{*}{ Defect } & \multirow{3}{*}{$\begin{array}{l}\text { Temperature } \\
\text { range } \\
\text { (K) }\end{array}$} & \multicolumn{2}{|c|}{ Emission rate data } & \multicolumn{2}{|c|}{ Capture rate data } & \multicolumn{3}{|c|}{ Calculated ionization energy parameters } \\
\hline & & - & - & - & - & - & - & - \\
\hline & & $\begin{array}{c}\beta \\
\left(\mathrm{s}^{-1} \mathrm{~K}^{-2}\right)\end{array}$ & $\begin{array}{c}E_{a} \\
(\mathrm{eV})\end{array}$ & $\begin{array}{c}\sigma_{\infty} \\
\left(\mathrm{cm}^{2}\right)\end{array}$ & $\begin{array}{c}E_{b} \\
(\mathrm{eV})\end{array}$ & $\begin{array}{l}E_{i 0} \\
(\mathrm{eV})\end{array}$ & $\begin{array}{c}\alpha^{\prime} \\
(\mathrm{eV} / \mathrm{K})\end{array}$ & $\begin{array}{c}\alpha \\
(\mathrm{eV} / \mathrm{K})\left({ }^{e}\right)\end{array}$ \\
\hline & & \multicolumn{7}{|c|}{ ELECTRON TRAPS } \\
\hline «A $»\left({ }^{a}\right)$ & $270-300$ & $2 \times 10^{7}$ & $0.825 \pm 0.01$ & $10^{-14}\left({ }^{d}\right)$ & $0.08\left(^{d}\right)$ & $0.755 \pm 0.01$ & $1.9 \times 10^{-4}$ & $2.5 \times 10^{-4}$ \\
\hline \multirow[t]{2}{*}{$《 B »\left({ }^{a}\right)$} & $240-280$ & $2 \times 10^{7}$ & $0.575 \pm 0.01$ & $10^{-14}\left({ }^{d}\right)$ & $0.16\left({ }^{d}\right)$ & $0.415 \pm 0.01$ & $1.9 \times 10^{-4}$ & $2.5 \times 10^{-4}$ \\
\hline & & \multicolumn{7}{|c|}{ HOLE TRAPS } \\
\hline \multirow[t]{2}{*}{ «A» $\left({ }^{b}\right)$} & $200-220$ & $2.2 \times 10^{8}\left({ }^{b}\right)$ & $0.40\left(^{b}\right)$ & $1.5 \times 10^{-15}\left({ }^{b}\right)$ & $-0.03\left({ }^{b}\right)$ & 0.43 & $4.0 \times 10^{-4}$ & $(4.6-5.2) \times 10^{-4}$ \\
\hline & & $1.1 \times 10^{8}\left({ }^{c}\right)$ & $0.41(c)$ & & & 0.45 & $4.5 \times 10^{-4}$ & $(4.0-4.6) \times 10^{-4}$ \\
\hline \multirow[t]{2}{*}{ «B» $\left({ }^{b}\right)$} & $310-350$ & $2.6 \times 10^{7}\left(b^{b}\right)$ & $0.71(b)$ & $1.7 \times 10^{-15}\left({ }^{b}\right)$ & $0\left({ }^{b}\right)$ & 0.71 & $1.8 \times 10^{-4}$ & $(2.4-3.0) \times 10^{-4}$ \\
\hline & & $4.5 \times 10^{7}\left({ }^{c}\right)$ & $0.73(\mathfrak{c})$ & & & 0.76 & $3.0 \times 10^{-4}$ & $(2.9-3.5) \times 10^{-4}$ \\
\hline $\mathrm{Fe}\left({ }^{b}\right)$ & $280-320$ & $5.5 \times 10^{5}(b)$ & $0.52(b)$ & $5.7 \times 10^{-18}$ & -0.07 & 0.59 & $3.4 \times 10^{-4}$ & $(4-4.6) \times 10^{-4}$ \\
\hline
\end{tabular}
capture rates be measured in the same temperature

\section{TABLE I}

Temperature coefficients of ionization energies for two electron traps and three hole traps in GaAs, as calculated from experimental quantities according to eqs. (5) and (6) 
range ; another precaution is to use samples with low carrier concentration, in order to avoid the possible influence of the free carriers upon the total capture cross-section (through Auger capture, or otherwise); finally, one should check - by varying either the applied reverse bias, or the doping level of the samples - that the influence of the electric field on the measured emission rates $[10,11]$ is negligible.

Let us consider, as an illustrating example, some of the available data for GaAs. In table I we summarize, for two electron and three hole traps, the experimental parameters, from which values of $\alpha^{\prime}$ and $\alpha$, as given in the last two columns, are deduced.

We comment briefly the values obtained for the temperature coefficient $\alpha$, keeping in mind the discussion in ref. [1] and the fact that the GaAs band gap has a temperature coefficient $\alpha_{G}=5 \times 10^{-4} \mathrm{eV} / \mathrm{K}$ [12]. Consider first the electron traps. Trap « $\mathrm{A}$ » (which has been tentatively attributed to oxygen on As site) is located at the middle of the gap and its $\alpha$ is about $0.5 \alpha_{\mathrm{G}}$, so that the relative position of the level in the gap appears to be independent of temperature. In $\mathrm{GaP}$, the $0_{p}$ electron level has been shown [1] to be pinned to the conduction band, however the situation in GaAs may well be different because the lowest conduction band in GaAs has a very low density of states so that the deep donor state is more closely associated with the $X$ and $L$ minima [13] which are at considerably higher energy. The «B » trap, of unknown origin but most probably a lattice defectimpurity complex [14], has a rather large $\alpha$ when its position in the gap (at less then one-third of the gap from $E_{\mathrm{c}}$ ) is considered.

The hole trap results are more striking; in particular for the " $A$ " trap, $\alpha \simeq \alpha_{G}$ indicating that this (acceptor-like) level is strongly pinned to the conduction band. According to ref. [1], this behaviour is typical for an acceptor state due to a $(\mathrm{Ga})$ vacancy; this assignment also agrees with band-theoretical calculations [15], but it is not supported by the fact that trap " $A$ " is characteristic for liquid-phase epitaxy material $[6,16,17]$. On the other hand, the fact that $\alpha$ is also very large for the state associated with $\mathrm{Fe}$ impurity is difficult to understand since this is a coulombic defect. For trap « B », as well as for other hole or electron traps not mentioned in table I, the results exhibit a rather large dispersion so that it appears that more precise experiments are needed for them.

We are grateful to N. Braslau, A. Mircea-Roussel, G. M. Martin, A. M. White, M. Jaros, A. Majerfeld and D. V. Lang for very useful discussions.

\section{References}

[1] Van Vechten, J. A. and Thurmond, C. D., IBM Rpt RC 5740 (1975) and Phys. Rev. B 14 (1976) 3539.

[2] Kopylov, A. A. and Pikhtin, A. N., Sov. Phys. Semicond. 8 (1975) 1563.

[3] Sah, C. T., Forbes, L., Rosier, L. L. and Tasch, A. F., Jr., Solid State Electron. 13 (1970) 759.

[4] Lang, D. V., J. Appl. Phys. 45 (1974) 3014.

[5] Henry, C. H. and Lang, D. V., Phys. Rev. B, to be published.

[6] LANG, D. V. and LogaN, R. A., J. Electron. Mater. 4 (1975) 1053.

[7] Mircea, A. and Mitonneau, A., Appl. Phys. 8 (1975) 15.

[8] Lang, D. V. and Logan, R. A., J. Appl. Phys. 47 (1976) 1533.

[9] Lang, D. V., Cho, A. Y., Gossard, A. C., Ilegems, M. and Wiegmann, W., J. Appl. Phys. 47 (1976) 2558.

In this work, as well as in ref. [7], the degeneracy factors are neglected. Their effect is to increase by a factor of 2 to 4 the apparent disagreement mentioned in the text.
[10] Walker, J. W., Sah, C. T., Phys. Rev. B 8 (1973) 5597.

[11] Herman III, J. M., SaH, C. T., Phys. Stat. Sol. (a) 14 (1972) 405.

Buxo, J. et al., C. R. Hebd. Séan. Acad. Sci. 282 (5 avril 1976).

[12] Thurmond, C. D., J. Electrochem. Soc. 122 (1975) 1133.

[13] Jaros, M., J. Phys. C (Solid State Phys.) 8 (1975) 2455 and private communication.

[14] Mircea, A., Mitonneau, A., Hollan, L. and Brière, A., Appl. Phys. 11 (1976) 187.

[15] Jaros, M. and Brand, S., Phys. Rev. B (15 oct. 1976)

[16] Hasegawa, F. and Majerfeld, A., Electron. Lett. 11 (1975) 286.

[17] Mitonneau, A., Martin, G. M. and Mircea, A., Proc. 6th Int. Symp. on GaAs and related compounds, Edinburgh, Sept. 1976. 